\title{
Awareness and Prevalence of Hepatitis C Virus Infection Among Pregnant Women in Nigeria: A National Pilot Cross-Sectional Study
}

GEORGE UCHENNA ELEJE ( $\square$ georgel21@yahoo.com )

Nnamdi Azikiwe University https://orcid.org/0000-0002-0390-2152

Ayyuba Rabiu

Bayero University

Ikechukwu Innocent Mbachu

Nnamdi Azikiwe University Faculty of Preliminary Studies: Nnamdi Azikiwe University

Godwin Otuodichinma Akaba

University of Abuja

Olabisi Morebise Loto

Obafemi Awolowo University

Hadiza Abdullahi Usman

University of Maiduguri

Preye Owen Fiebai

University of Port Harcourt

Rebecca Chinyelu Chukwuanukwu

Nnamdi Azikiwe University

Ngozi Nneka Joe-lkechebelu

Chukwuemeka Odumegwu Ojukwu University

Chike Henry Nwankwo

Nnamdi Azikiwe University

Stephen Okoroafor Kalu

Nnamdi Azikiwe University Teaching Hospital

Chinyere Ukamaka Onubogu

Nnamdi Azikiwe University

Chukwuanugo Nkemakonam Ogbuagu

Nnamdi Azikiwe University

Shirley Nneka Chukwurah

Nnamdi Azikiwe University

Chinwe Elizabeth Uzochukwu

Nnamdi Azikiwe University

Samuel Oluwagbenga Inuyomi 
Obafemi Awolowo University

Bukola Abimbola Adesoji

Obafemi Awolowo University Teaching Hospital Complex

\section{Uchenna Chukwunonso Ogwaluonye}

Nnamdi Azikiwe University

\section{Ekene Agatha Emeka}

Nnamdi Azikiwe University

\section{Richard Obinwanne Egeonu}

Nnamdi Azikiwe University Teaching Hospital

Odion Emmanuel Igue

Obafemi Awolowo University

Chiamaka Henrietta Jibuaku

Nnamdi Azikiwe University

\section{Ogbonna Dennis Okoro}

University of Maiduguri

\section{Prince Ogbonnia Aja}

Nnamdi Azikiwe University Faculty of Preliminary Studies: Nnamdi Azikiwe University

\section{Chiamaka Perpetua Chidozie}

Nnamdi Azikiwe University

\section{Hadiza Sani Ibrahim}

Obafemi Awolowo University

\section{Fatima Ele Aliyu}

Bayero University

\section{Aisha Ismaila Numan}

University of Maiduguri

\section{Solace Amechi Omoruyi}

University of Port Harcourt Teaching Hospital

ljeoma Chioma Oppah

University of Port Harcourt Teaching Hospital

\section{Ubong Inyang Anyang}

University of Abuja Teaching Hospital

\section{Aishat Ahmed}

University of Abuja Teaching Hospital

\section{Osita Samuel Umeononihu}

Nnamdi Azikiwe University

\section{Eric Okechukwu Umeh}

Nnamdi Azikiwe University

\section{Sussan Ifeyinwa Nweje}

Nnamdi Azikiwe University Teaching Hospital 


\section{Ifeoma Clara Ajuba}

Nnamdi Azikiwe University

Chukwuemeka Chukwubuikem Okoro

Nnamdi Azikiwe University Teaching Hospital

Ifeanyi Kingsley Nwaeju

Nnamdi Azikiwe University Teaching Hospital

Arinze Anthony Onwuegbuna

Nnamdi Azikiwe University

Ibrahim Adamu Yakasai

Bayero University

Oliver Chukwujekwu Ezechi

Nigerian Institute of Medical Research

Joseph Ifeanyichukwu Ikechebelu

Nnamdi Azikiwe University

\section{Research}

Keywords: Awareness, hepatitis C, pregnancy, prevalence, risk factor, screening

Posted Date: March 23rd, 2021

DOI: https://doi.org/10.21203/rs.3.rs-336260/v1

License: (c) (i) This work is licensed under a Creative Commons Attribution 4.0 International License. Read Full License 


\section{Abstract}

Background: Although hepatitis C virus (HCV) may constitute one of the viral hepatitis with high burden in Nigeria, there is no national data on its awareness and burden among pregnant women to justify its routine screening.

Objectives: To investigate awareness, seroprevalence and risk factors for HCV infection among pregnant women in Nigeria.

Methods: A total of 159 pregnant women from antenatal clinics across the six geopolitical zones in Nigeria consented to anti-HCV testing by third generation ELISA and confirmed using polymerase chain reaction technique. Confirmed HCV positive women were further tested for hepatitis B and HIV. The women were evaluated for the presence of known risk factors for HCV infection. Odds ratios (ORs), adjusted ORs (aORs) and their $95 \%$ confidence intervals (Cls) were determined and p-values of $<0.05$ were considered significant.

Findings: Of the 159 participants, $77(48.4 \% ; 95 \% \mathrm{Cl}, 38.2 \%$ to $60.5 \%)$ were aware of HCV infection and awareness of HCV was associated with participants' young age (OR=2.21; $95 \% \mathrm{Cl}=1.16$ to 4.21$)$, high educational level $(\mathrm{OR}=3.29 ; 95 \% \mathrm{Cl}=1.63$ to 6.64$)$ and participants' occupation $(\mathrm{OR}=0.51 ; 95 \% \mathrm{Cl}=0.26$ to 0.99). In multivariable logistic regression, adjusted for confounders, the association between awareness of HCV and participants' young age $(\mathrm{aOR}=1.60 ; 95 \% \mathrm{Cl}=1.09$ to $2.35 ; \mathrm{p}=0.018)$ and high educational level (aOR=1.48; $95 \% \mathrm{Cl}=1.17$ to $1.86 ; \mathrm{p}=0.001$ )remained significant. $\mathrm{HCV}$ seroprevalence was found to be $1.3 \%$ (95\% $\mathrm{Cl}=0.2 \%$ to $4.5 \%)$. All $(100.0 \%, 95 \% \mathrm{Cl}=12.1$ to $100.0 \%)$ the HCV-positive participants and $99(63.1 \%$, $95 \% \mathrm{Cl}=51.3 \%$ to $76.8 \%) \mathrm{HCV}$-negative participants had identifiable HCV risk factors. Dual seropositivity of anti-HCV/anti-HIV and anti-HCV/HBsAg each accounted for $1.3 \%$ and none of the participants was triply infected or mono-infected with HCV. The more commonly identified risk factors were multiple sexual partners, 25 (15.7\%), shared needles, 22 (13.8\%), and blood transfusion, 18 (11.3\%). The risk factor variables did not have significant association with HCV positive status.

Conclusion: There is lack of awareness regarding HCV infection among pregnant women in Nigeria and awareness is positively influenced by young age and high educational level. The prevalence of HCV is high and provides preliminary evidence to justify routine screening in antenatal clinics. There is also a need for enlightenment programs in communities and antenatal clinics.

\section{Funding}

TETFund National Research Fund 2019 (Grant number TETFund/DR\&D/CE/NRF/STI/33).

\section{Plain Language Summary}

Background: Although hepatitis C virus (HCV) may be one of the viral hepatitis with high load in Nigeria, there is no previous Nigerian study to identify its awareness rate and the frequency of the problem among 
pregnant women so as to know whether to be doing HCV test routinely in pregnancy.

Objectives: To examine awareness, frequency and risk factors for HCV infection among pregnant women in Nigeria.

Methods: A total of 159 pregnant women from antenatal clinics across the six geographical zones in Nigeria consented to HCV antibody testing and confirmed by using polymerase chain reaction method. Confirmed HCV positive women were further tested for hepatitis B and HIV. The women were assessed for the presence of known risk factors for HCV infection. Odds ratios (ORs), adjusted ORs (aORs) and their $95 \%$ confidence intervals $(\mathrm{Cls})$ were determined and $p$-values of $<0.05$ were considered significant.

Findings: Of the 159 participants, 77 (48.4\%) were aware of HCV infection and awareness of HCV was significantly associated with participants' young age, high educational level and participants' occupation. When the other confounding factors were removed, the association between awareness of HCV and participants' young age and high educational level remained significant. HCV constitute $1.3 \%$ of pregnant population. All the HCV-positive participants and 99 (63.1\%) HCV-negative participants had recognizable $\mathrm{HCV}$ risk factors. Double seropositivity of anti-HCV/anti-HIV and anti-HCV/HBsAg each accounted for $1.3 \%$ and none of the participants was infected by the three viruses or affected alone by HCV. The more commonly identified risk factors were multiple sexual partners $(15.7 \%)$, shared needle $(13.8 \%)$, and blood transfusion (11.3\%). The risk factors did not have significant association with HCV positive status.

Conclusion: There is lack of awareness regarding HCV infection among pregnant women in Nigeria and awareness is strongly influenced by young age and high educational level. The frequency of HCV is high and provides initial evidence to justify routine screening at the antenatal clinics. There is also a need for education programs in the communities and antenatal clinics on the existence of HCV to enhance prevention.

\section{Introduction}

Hepatitis C Virus may be one of the common infections among pregnant women in Nigeria, and worldwide approximately $8 \%$ of pregnant women have HCV infection, with the prevalence being as high as $4 \%$ in the United States [1]. According to the U.S. Centers for Disease Control and Prevention, an estimated 23,000 to 46,000 children in the United States live with HCV infection and values are expectedly more in East Asia and sub-Saharan Africa [2]. Although there is regional variability in the prevalence of $\mathrm{HCV}$ in Nigeria, the national data on its awareness and burden among pregnant women is lacking [2].

Since there is no guideline for routine screening of HCV and health promotional strategies during antenatal care in Nigeria, some pregnant women may not be aware of their HCV infection status, as HCV may not be mentioned by their healthcare providers [2]. Additionally, HCV infection is usually asymptomatic, so, most infected women may be unaware of their status until the incidental diagnosis of chronic HCV is made [3]. 
Although universal antenatal screening for HCV is largely debatable, prenatal diagnosis of HCV has a twofold benefit for mother and child [3]. Prenatal HCV screening helps to diagnose an unacknowledged infection by the mother. Furthermore, screening during pregnancy discloses HCV exposure status of the newborn, and provides opportunity for prevention of mother-to-child transmission (PMTCT) of HCV through prompt and appropriate follow-up after the birth. According to a recent review, the rate of motherto-child transmission of $\mathrm{HCV}$ is approximately $5 \%$ and perinatally infected children develop cirrhosis at an earlier age than those who acquire HCV as adolescents [3]. More so, HCV infection during pregnancy is associated with an increased risk of adverse fetal outcomes such as fetal growth restriction and low birth weight [3]. Therefore, there is need to intensify efforts at PMTCT of HCV $[3,4]$.

Eradication of the virus in pregnant women and women of childbearing age is the main target in the prevention and control of HCV infection. Surprisingly, not all hospitals in Nigeria offer prenatal screening for HCV and the awareness of the HCV infection among pregnant women has not been assessed nationally. Awareness of the risks associated with HCV infection during pregnancy among pregnant women will create more demands for HCV screening and PMTCT interventions among them. Some authorities have argued that routine antenatal screening for HCV is not a viable option in resourceconstrained settings because the information on the efficacy and safety of antivirals for HCV in pregnancy is generally lacking, and the treatment of HCV infection during pregnancy is not currently recommended [4, 5]. Nevertheless, intrauterine and peripartum transmission of HCV are both possible and higher rates are associated with a high maternal serum viral load and concomitant HIV or HBV infection, prolonged or difficult delivery, and invasive fetal monitoring during delivery. Therefore, infection during pregnancy and infancy needs to be investigated more to design management strategies most effectively [6]. This may help impact pregnancy care decisions and may involve limiting obstetrical practices that increase fetal exposure to maternal blood such as avoiding the prolonged rupture of membranes, invasive fetal monitoring, and episiotomy (in women who screen positive for $\mathrm{HCV}$ ) [7, 8]. In addition, knowledge of HCV infection during pregnancy may inform counseling about associated pregnancy risks such as cholestasis of pregnancy and preterm birth [7].

Hepatitis $\mathrm{C}$ virus prevalence in the maternal population mirrors that of the general population and obstetrics data could also help healthcare planners and caregivers to design and implement evidencebased interventions for HCV elimination [9]. The World Health Organization has called for HCV elimination as one of the major public health threat by 2030 [4]. Accordingly, the U.S. Preventive Services Task Force and the American Association for the Study of Liver Disease-Infectious Diseases Society of America 2019 guidelines recommend universal HCV screening for all individuals aged 18 years and older including pregnant women [4]. Routine universal screening for HCV in pregnancy at the first prenatal visit is therefore recommended so as to institute other non-pharmacological interventions [10]. Moreso, HCV screening will promote Sustainable Development goal 3, and general wellness for both mother and child.

There is currently no national data on the awareness and prevalence of HCV among pregnant women in Nigeria. This study was therefore undertaken to assess the awareness, seroprevalence and potential risk factors of HCV infections within the Nigerian national obstetric population. 


\section{Materials And Methods}

\section{Study design}

This was a multicenter national hospital-based cross-sectional pilot baseline study designed to explore the HCV awareness, the prevalence of HCV and factors affecting such awareness and prevalence rates among pregnant women.

\section{Study area}

The study was conducted in Nigeria, a country made up of 36 states and the Federal capital territory grouped into six geopolitical zones. Participants were recruited from one randomly selected tertiary level health facility in each of the five geopolitical zones in Nigeria apart from the South East zone where the lead institution for the TETFund National Research Fund 2019 was located. The sites randomly selected are: Aminu Kano Teaching Hospital, Kano [North-West zone]; Obafemi Awolowo University Teaching Hospital Complex, lle-Ife [South-West zone]; University of Port Harcourt Teaching Hospital, Port-Harcourt [South-South zone]; University of Abuja Teaching Hospital, Gwagwalada [North-Central zone]; University of Maiduguri Teaching Hospital, Maiduguri [North-East zone] in addition to the lead Institution, Nnamdi Azikiwe University Teaching Hospital, Nnewi [South-East zone]. A summary of the protocol is described here, and the complete protocol has previously been published [11].

\section{Study population}

The study was carried out among consenting pregnant women, who were attendees of the antenatal clinic in randomly selected health care facilities in each of the six geopolitical zones of Nigeria.

\section{Inclusion criteria}

Pregnant women registered for their antenatal care in the study sites were eligible to participate in the study.

\section{Exclusion criteria}

Non-pregnant women and women whose pregnancy could not be confirmed by ultrasound or blood test were excluded.

\section{Recruitment of participants}

We employed random sampling by selecting 6 tertiary hospitals across the 6 geopolitical zones in Nigeria. The research assistants were adequately trained in recruiting and screening pregnant women in the survey. Pregnant women were recruited from the antenatal clinics of each hospital over a one month (between June 2, 2020 and July 1, 2020) period. After detailed explanation of the objectives, procedures and possible benefits of the study, only those who accepted to participate in the study and gave a written informed consent were enrolled into the study. The participants were then interviewed using study 
specific tool. The study tool contained questions asking women whether they had heard of HCV infection, including whether they had specific risk factors for HCV such as past history of HBV, intravenous drug use, multiple sex partners, etc). Past history of HBV was defined as participants who previously tested positive to hepatitis B surface antigen. Intravenous drug use was defined as injection of chemicals into the body through a hypodermic needle into a vein. A person was defined to have multiple sex partners, when the person has sex with more than one person at the same time. Pregnant women who completed the survey, were asked for their contact details and given a sole identifier; a research team member cross checked these details to ensure each woman finished the survey questions. Thereafter, blood sample was collected for HCV determination.

\section{Laboratory procedure and analysis}

Five milliliters of the blood sample was aseptically collected by venipuncture from each pregnant woman into a plain specimen bottle after consent was sought and obtained. The participant's code, age, time and date of collection were labeled on the bottle for proper identification. Each of the samples was centrifuged at 3,000/rpm for $5 \mathrm{~min}$ and the serum portion was used on the test strip for antigen or antibody detection. Sera samples were stored at $-25^{\circ} \mathrm{C}$ in line with the kit manufacturer's instruction until screened for HBsAg, anti-HIV, and anti-HCV antibodies. Screening for Anti-HCV antibodies was conducted using the Enzyme-linked immunosorbent assay (ELISA) kit manufactured by LabACON (Hangzhou Biotest Biotech Company, Ltd., China) which has a specificity of $99.0 \%$ and a sensitivity of $99.9 \%$ according to manufacturer declared figures. The kit has in-built controls. The manufacturer's instruction was strictly followed and executed by trained research assistants in each facility. The results were reported as positive or negative. The Anti-HCV antibodies tests were confirmed using DNA PCR analysed centrally at Molecular Virology Laboratory, NAUTH, Nnewi, Nigeria. Serial rapid HIV testing was done according to Nigerian National HIV testing guidelines viz. Alere Determine HIV-1/2 (Alere Medical Co. Ltd., Matsudo, Japan) test kit as a screening test, followed by the Uni-Gold Recombigen ${ }^{\circledR}$ HIV-1/2 (Trinity Biotech, Ireland) assay if positive and finally confirmed by HIV1/2 STAT-PAK (Chembio Diagnostic Systems, Inc., USA). The HBsAg were tested using an ELISA kit manufactured by LabACON (Hangzhou Biotest Biotech Company, Ltd., China).

\section{Study Endpoints}

The primary endpoint was the awareness and seroprevalence of HCV. The other measures of interest included patient demographics, risk factors for HCV, and medical history.

\section{Sample size determination}

No formal sample size calculations were made because of the preliminary nature of the study [12].

\section{Statistical analysis}


The data were entered into an Excel 2016 spreadsheet (Microsoft Corporation, Redmond, WA, USA) and subsequently was imported into Statistical Package for the Social Sciences (SPSS) Version 22.0 (IBM Corp., Armonk, NY, USA). Statistical analyses were performed with Statistical Package for the Social Sciences (SPSS) Version 22.0 (IBM Corp., Armonk, NY, USA). The bivariate analysis was performed using a Pearson's chi-square test or Fisher's exact test, whenever appropriate, to compare the demographic characteristics (e.g., age, marital status) as well as risk factors for HCV (e.g., occupational sex worker, multiple sex partner) and awareness and prevalence rates. Conditional logistic regression was employed in the multiple regression analysis to determine variables associated with awareness of HCV, while controlling for other confounding variables (such as: religion, marital status, and ownership of housing). In this analysis, the odds ratio (ORs), adjusted ORs (aORs) and confidence interval was set at $95 \%$ and $\mathrm{p}<0.05$ was considered significant.

\section{Ethical consideration}

Written consent was obtained from all participants before recruitment into the study. Ethical clearance for this study was obtained from the National Health Research Ethics Committee, with registration number: NHREC/01/01/2007-23/01/2020 (approval date: January 23, 2020) in accordance with the Helsinki's code of conduct for biomedical research involving human subjects. Strengthening the Reporting of Observational Studies in Epidemiology (STROBE) guidance was used for reporting. Full details of the study are in the protocol [11].

\section{Results}

During the one-month pilot study period, 159 participants were enrolled into the study. The data of the 159 participants was reported. The flow chart is shown in Figure 1. The result of the bivariate analysis of the association between HCV infection awareness and respondents' socio-demographic characteristics is shown in Table 1 while Table 2 shows the association between hepatitis $C$ awareness and respondents' socio-demographic characteristics based on bivariate test and multiple logistic regressions.

Of the 159 participants, 77 (48.4\%; 95\% Cl, 38.2\% to 60.5\%) were aware of HCV infection. HCV awareness was found to be associated with participants' age $(p=0.018)$ and educational level $(p=0.001)$, but not with religion, unmarried status, occupation or residing in a rented apartment. Two participants screened and confirmed positive for $\mathrm{HCV}$, giving an $\mathrm{HCV}$ prevalence of $1.3 \%(95 \% \mathrm{Cl}=0.2 \%$ to $4.5 \%)$. All the two $\mathrm{HCV}$ positive participants $(100.0 \%, 95 \% \mathrm{Cl}=12.1$ to $100.0 \%)$ and $99(63.1 \%, 95 \% \mathrm{Cl}=51.3 \%$ to $76.8 \%) \mathrm{HCV}$ negative participants had identifiable HCV risk factors ( $p>0.05)$. Dual seropositivity of anti-HCV/anti-HIV and anti-HCV/HBsAg each accounted for $1.3 \%$ and none of the participants was triply infected or monoinfected with HCV.

Table 3 shows the association between awareness of hepatitis c virus and respondents' risk factors for HCV infection. The commonest identified risk factors included multiple sexual partners, 25 (15.7\%), shared needles, 22 (13.8\%), and blood transfusion, 18 (11.3\%). 
The association between HCV status and respondents' risk factors for HCV is shown in Table 4. The risk factors variables (histories of multiple sexual partnership $(p=0.231)$, shared needle $(p=0.193)$, blood transfusion $(p=0.793)$, etc) did not have significant association with HCV positive status.

\section{Discussion}

This study reveals the high awareness gaps and burden of HCV among pregnant women in Nigeria. In this study only $48.4 \%$ of the participants were aware of HCV infection and such awareness was significantly influenced by young participants' age $(p=0.018)$ and high educational level $(p=0.001)$. The prevalence of HCV was $1.3 \%$ and all the HCV-positive participants and $63.1 \%$ of HCV-negative participants had identifiable HCV risk factors. All the HCV positive cases were either dually infected with HIV or HBsAg. None of the participants was triply infected for HCV, HBV and HIV or mono-infected with HCV. The identified risk factors did not have significant association with HCV positive status.

Our findings identified awareness gaps for HCV infection among pregnant women in Nigeria with less than $50 \%$ being aware of HCV infection. This was in contrast with findings from a study in the USA conducted among pregnant women with opioid use disorder in which $97 \%$ were aware of HCV [13]. The high awareness gaps among our study participants might be due to difference in study populations. While our study involved all pregnant women attending antenatal clinics, the quoted study from the USA [13] involved only pregnant women with opioid use disorder who may have been previously reached with messages regarding HCV by their healthcare providers in the course of discussing the implications of opioid use and infections that could be transmitted by intravenous drug users. The differences in the epidemiology of HCV in the study settings may be an additional reason for the observed differences in awareness levels. The low awareness of hepatitis $\mathrm{C}$ infection among the study participants is worrisome and calls for need for more health education on hepatitis $\mathrm{C}$ and other infections among pregnant women in Nigeria. The antenatal care provides a big opportunity to offer pregnant women health education including hepatitis $\mathrm{C}$ infection. The finding from this study makes the case for provider counseling and education at the time of antenatal booking and care for pregnancy.

Our study has also revealed that the level of awareness was positively influenced by young age $(p=0.018)$ and high educational level $(p=0.001)$. These findings are understandable because younger women and women with high educational levels may be more likely to seek healthcare related information. In a recent Ethiopian study, young age (17-25 years) was a significant predictor of HCV infection [14], while a previous report [15] from the same country revealed high HCV status among pregnant women with higher education level.

The seroprevalence of anti-HCV antibodies of $1.3 \%$ was higher than $0.5 \%$ reported previously in Anyigba, Nigeria by Omatola et al [16] and 0.3\% reported in India by Parveen et al [17] in an antenatal population in India, but similar to $1.6 \%$ reported in a recent Ethiopian study by Dagnew et al [14]. However, this rate was lower than 3.9\% reported by Okusanya et al in Irrua, Nigeria [18] as well as findings of other epidemiological studies that revealed a prevalence of 2 to $4 \%[16,19,20]$. Our findings were also lower 
than $8.07 \%$ found in a study in Ethiopia [17]. In a systematic review involving 26 studies conducted by the $\mathrm{CDC}$ on $\mathrm{HCV}$ infection during pregnancy, the HCV-positive prevalence was $1.2 \%$ [21].

As revealed in this study, HCV prevalence has no statistically significant association with any of the potential risk factors for HCV even though it was higher among participants with histories of multiple sexual partners and shared needles. This finding is analogous to a previous Nigerian study by Okusanya et al [18] as well as an Ethiopian report by Dabsu and Ejeta [15]. Moreover, since both HIV and HCV or HBV and HCV share common risk factors and mode of transmission, it will be equally important to incorporate information on HCV risk factors into HIV/AIDS and HBV intervention strategies in Nigeria as an alternative. On the other hand, to drastically reduce the prevalence of this deadly disease in Nigeria, a nationwide health promotional campaign should be done to help create awareness regarding HCV infection.

Unlike findings from a previous study in Keffi, Nigeria by Oti et al [22] where no pregnant woman was coinfected with HCV and HBV, our report revealed that no woman was mono-infected with HCV and $1.3 \%$ had HCV/HBV or HCV/HIV. Our overall HCV-HIV co-infection of $1.3 \%$ was similar to $1.5 \%$ reported by Ezechi et al in Lagos, Nigeria among HIV-positive pregnant population [23] but lower than $2.9 \%$ reported in Ethiopia [15].

The Society of Gynecology and Obstetrics of Nigeria (SOGON) has recently advised for routine screening of pregnant women for HCV infection in Nigeria. However, in 2018, universal hepatitis C screening during pregnancy was recommended by the American Association for the Study of Liver Diseases and the Infectious Diseases Society of America. Since that time, the and Centers for Disease Control and Prevention (CDC) United States Preventive Task Force (USPSTF) have updated their previous guidance and specifically recommended screening for all pregnant women during each pregnancy, except in settings where the prevalence of HCV infection is $<0.1 \%$ [21]. By extension, this guideline should apply to Nigerian settings since the prevalence of HCV in Nigeria in this study is $1.3 \%$. These guidelines all acknowledge the cost-effectiveness of universal screening and the inadequacies of risk-based screening. However, in the absence of endorsement of these guidelines from the obstetrics societies, screening practices will likely remain non-uniform across obstetrics practice units in the United States [7].

The clinical importance of this study was that pregnancy is one of the few points of contact women of reproductive age have with their healthcare providers; therefore, pregnancy provides a crucial time for targeting this population for HCV screening. Children also benefit from maternal screening, because the primary route of infection in children is vertical transmission during pregnancy, and children are not routinely assessed for liver disease [1]. Universal screening offers several advantages that position us for a future where HCV treatment in pregnancy can happen and offers us progress toward the elimination of HCV [24]. Our experience underscores the importance of obtaining information about at-risk behavior. Although universal HCV screening will identify patients who fail to acknowledge risk behaviors, discussing HCV and the medical complications associated with acquiring HCV in pregnancy and its 
mother-to-child transmission should also be part of prenatal counseling. Future research should evaluate the impact of this prenatal screening guideline on clinical practice.

The strength of this study is the multicenter study site design and appears to be the first national study in Nigeria to evaluate the HCV awareness rate among pregnant women population to the best of the authors knowledge. Additionally, studies have shown that after using a screening assay, a confirmatory test to confirm anti-HCV status was needed; this was provided by the HCV RNA testing carried out to confirm the HCV infection in this study $[1,3]$. Since the study design was cross-sectional and the data was preliminary, it shares the shortcoming of constructing cause and effect relationship. There are some limitations. For instance, although our present protocol included determination of rates of seroconversion for these viral infections in pregnancy, we could not evaluate for seroconversion or birth outcomes in our present preliminary findings, which is an important reminder that women can remain at risk for new HCV infections even during pregnancy [11]. Awareness of HCV could be quite challenging in some settings where people may confuse HCV, hepatitis A virus (HAV), and HBV. However, we avoided this confusion by interpreting the questionnaires in vernacular language.

\section{Conclusion}

The awareness of HCV infection among pregnant women in Nigeria is less than $50 \%$ and it is positively influenced by younger age and higher educational level. HCV prevalence rate was $1.3 \%$ and none of the

known risk factors was significantly associated with it. Although the results of the completed survey with a larger study sample would provide more clarity in the awareness and prevalence of HCV, routine screening may be a viable option.

\section{Abbreviations}

CDC: Centers for Disease Control and Prevention

HAV: Hepatitis A virus

HBsAg: Hepatitis B surface antigen

HBV: Hepatitis B virus

HCV: Hepatitis C virus

HIV: Human immuno deficiency virus

SOGON: Society of Gynecology and Obstetrics of Nigeria

TETFund: Tertiary Education Trust Fund

USPSTF: United States Preventive Task Force 


\section{Declarations}

\section{Acknowledgements}

The authors would like to thank all the pregnant women who shared their hepatitis $\mathrm{C}$ awareness status and consented for HCV screening and its co-infections. We also thank all the staff of the hospitals involved in this study.

\section{Author's contribution:}

GU Eleje, II Mbachu, A Rabiu, GO Akaba, PO Fiebai, O Loto, HA Usman, CU Onubogu, UC Ogwaluonye, and SO Kalu contributed to the study conceptualization and methodology; RO Egeonu, C Jibuaku, P Aja, CP Chidozie, HS Ibrahim, FE Aliyu, EO Igue, B Adosoji, AI Numan, OD Okoro, SA Omoruyi, IC Oppah, UI Anyang, SO Inuyomi and A Ahmed conducted the clinic study, ensured completion of the participants data and documented the required data; $\mathrm{CH}$ Nwankwo and GU Eleje analyzed the data and drafted the original manuscript; CE Uzochukwu, SI Nweje, SN Chukwurah, OS Umeononihu, RC Chukwuanukwu, EO Umeh, EA Emeka, CC Okoro, IK Nwaeju, AA Onwuegbuna and CN Ogbuagu worked on formal analysis; NN Joe-lkechebelu, IC Ajuba, O Ezechi, IA Yakasai and JI Ikechebelu contributed to the project administration, writing (review and editing), data visualization, and supervision. All authors have seen and approved their contributions and the final version of the manuscript.

\section{Disclosure statement for publication:}

All authors have made substantial contributions to: conception and design of the study, or acquisition of data, or analysis and interpretation of data; drafting the article or revising it critically for important intellectual content; and final approval of the version submitted. This manuscript has not been submitted for publication in another journal.

\section{Ethics approval and consent to participate}

Ethical approval was obtained from National Health Research Ethics Committee, Abuja and Health Research Ethics Committees of the 6 tertiary hospitals. Informed written consent was obtained from the participants.

\section{Consent for publication}

Not applicable

\section{Competing interests}

The authors declare that they have no competing interests.

\section{Data Availability}

The data used to support the findings of this study are available from the site publicly. 


\section{Funding}

This work was funded by TETFund National Research Fund 2019 [Grant number

TETFund/DR\&D/CE/NRF/STI/33]. The views expressed in this publication are those of the author(s) and not necessarily those of the TETFund. The funders had no role in the design of the study or writing of the manuscript. The corresponding author had full access to all the data in the study and had final responsibility for the decision to submit for publication.

\section{References}

1. Saab S, Kullar R, Gounder P. The Urgent Need for Hepatitis C Screening in Pregnant Women: A Call to Action. Obstet Gynecol. 2020 Apr;135(4):773-777. doi: 10.1097/AOG.0000000000003704.

2. Bigna JJ, Kenne AM, Hamroun A, Ndangang MS, Foka AJ, Tounouga DN, et al. Gender development and hepatitis $B$ and $C$ infections among pregnant women in Africa: a systematic review and metaanalysis. Infect Dis Poverty. 2019 Mar 4;8(1):16. doi: 10.1186/s40249-019-0526-8.

3. Ragusa R, Corsaro LS, Frazzetto E, Bertino E, Bellia MA, Bertino G. Hepatitis C Virus Infection in Children and Pregnant Women: An Updated Review of the Literature on Screening and Treatments. AJP Rep. 2020 Jan;10(1):e121-e127. doi: 10.1055/s-0040-1709185.

4. Freriksen JJM, van Seyen M, Judd A, Gibb DM, Collins IJ, Greupink R, et al. Review article: directacting antivirals for the treatment of HCV during pregnancy and lactation - implications for maternal dosing, foetal exposure, and safety for mother and child. Aliment Pharmacol Ther. 2019 Oct;50(7):738-750. doi: 10.1111/apt.15476.

5. Hong J, Kushner T, Dieterich D, Garry D, Marcos LA, Beneri C, et al. Reducing mother-to-child transmission of HCV: Is it attainable with a multidisciplinary approach? J Hepatol. 2019 Jul;71(1):229-230. doi: 10.1016/j.jhep.2019.01.032.

6. El-Shabrawi MHF, Kamal NM, Mogahed EA, Elhusseini MA, Aljabri MF. Perinatal transmission of hepatitis C virus: an update. Arch Med Sci. 2019 Mar 15;16(6):1360-1369. doi: 10.5114/aoms.2019.83644.

7. Kushner T, Park C, Masand D, Wagner B, Grace M, Rosenbluth E, et al. Hepatitis C Seroprevalence Among Consecutive Labor and Delivery Admissions in Two New York City Hospitals. Open Forum Infect Dis. 2020 Oct 23;7(11):ofaa514. doi: 10.1093/ofid/ofaa514.

8. US Preventive Services Task Force, Owens DK, Davidson KW, Krist AH, Barry MJ, Cabana M, et al. Screening for Hepatitis C Virus Infection in Adolescents and Adults: US Preventive Services Task Force Recommendation Statement. JAMA. 2020 Mar 2. doi: 10.1001/jama.2020.1123.

9. Sheffield JS, Argani CH. Hepatitis $C$ Virus Infection in the Pregnant Woman: Is It Time for Universal Screening? Obstet Gynecol. 2020 Apr; 135(4):770-772. doi: 10.1097/AOG.0000000000003815.

10. Spera AM, Eldin TK, Tosone G, Orlando R. Antiviral therapy for hepatitis C: Has anything changed for pregnant/lactating women? World J Hepatol. 2016 Apr 28;8(12):557-65. doi:

10.4254/wjh.v8.i12.557. 
11. Eleje GU, Mbachu II, Ogwaluonye UC, Kalu SO, Onubogu CU, Nweje SI, et al. Prevalence, seroconversion and mother-to-child transmission of dual and triplex infections of HIV, hepatitis B and C viruses among pregnant women in Nigeria: study protocol. Reprod Health. 2020 Sep 25;17(1):144. doi: 10.1186/s12978-020-00995-8.

12. Noordzij M, Tripepi G, Dekker FW, Zoccali C, Tanck MW, Jager KJ. Sample size calculations: basic principles and common pitfalls. Nephrol Dial Transplant. 2010;25(5):1388-93.

13. Krans EE, Rothenberger SD, Morrison PK, Park SY, Klocke LC, Turocy MJ, Zickmund S. Hepatitis C Virus Knowledge Among Pregnant Women with Opioid Use Disorder. Matern Child Health J. 2018 Aug;22(8):1208-1216. doi: 10.1007/s10995-018-2506-1.

14. Dagnew M, Million Y, Gizachew M, Eshetie S, Yitayew G, Asrade L, Adefris M, Moges F, Tiruneh M. Hepatitis B and C Viruses' Infection and Associated Factors among Pregnant Women Attending Antenatal Care in Hospitals in the Amhara National Regional State, Ethiopia. Int J Microbiol. 2020 Oct 9;2020:8848561. doi: 10.1155/2020/8848561.

15. Dabsu R, Ejeta E. Seroepidemiology of Hepatitis Band C Virus Infections among Pregnant Women Attending Antenatal Clinic in Selected Health Facilities in East Wollega Zone, West Oromia, Ethiopia. Biomed Res Int. 2018 Dec 10;2018:4792584. doi: 10.1155/2018/4792584.

16. Omatola $\mathrm{CA}$, Okolo MO, Abraham JO. Hepatitis $\mathrm{C}$ virus coinfection in human immunodeficiency virus infected pregnant women in Anyigba, Kogi State, Nigeria. Nat Sci 2018;16:62-68.

17. Malhotra P, Nanda S, Malhotra V, Chauhan M, Malhotra N, Chugh A, et al. Prevalence of HIV, hepatitis $B$, hepatitis $C$ in pregnancy at tertiary care center of Northeren India. Adv Res Gastroentero Hepatol 2016;1(4): 80-82.

18. Okusanya BO, Aigere EO, Eigbefoh JO, Ikheloa J. Seroprevalence and clinico-epidemiological correlates of hepatitis $\mathrm{C}$ viral antibodies at an antenatal booking clinic of a tertiary hospital in Nigeria. Arch Gynecol Obstet. 2013 Sep;288(3):495-500. doi: 10.1007/s00404-013-2773-4.

19. Kabinda JM, Akilimali TS, Miyanga AS, Donnem P, Michele D. Hepatitis B, hepatitis C and HIV in pregnant women in the community in the Democratic Republic of Congo. World J AIDS 2015; 5(2):124-130.

20. Opaleye OO, Igboama MC, Ojo JA, Odewale G. Seroprevalence of HIV, HBV, HCV, and HTLV among Pregnant Women in Southwestern Nigeria. J Immunoassay Immunochem. 2016;37(1):29-42. doi: 10.1080/15321819.2015.1040160.

21. Schillie S, Wester C, Osborne M, Wesolowski L, Ryerson AB. CDC Recommendations for Hepatitis C Screening Among Adults - United States, 2020. MMWR Recomm Rep. 2020 Apr 10;69(2):1-17. doi: 10.15585/mmwr.rr6902a1.

22. Oti BV, Pennap GR, Ngari HR. HBsAg and Anti-HCV Prevalence among Pregnant Women Accessing Antenatal Care in a Tertiary Healthcare Facility in Central Nigeria. Hepatol Pancreat Sci. 2018;2(1): 14. doi:10.4172/ 2573-4563.1000110.

23. Ezechi OC, Kalejaiye OO, Gab-Okafor CV, Oladele DA, Oke BO, Musa ZA, et al. Sero-prevalence and factors associated with Hepatitis B and C co-infection in pregnant Nigerian women living with HIV 
infection. Pan Afr Med J. 2014 Mar 13;17:197. doi: 10.11604/pamj.2014.17.197.2310.

24. Jhaveri R, Broder T, Bhattacharya D, Peters MG, Kim AY, Jonas MM. Universal Screening of Pregnant Women for Hepatitis C: The Time Is Now. Clin Infect Dis. 2018 Oct 30;67(10):1493-1497. doi: $10.1093 /$ cid/ciy586.

\section{Tables}

Due to technical limitations, table $1,2,3,4$ is only available as a download in the Supplemental Files section.

\section{Figures}




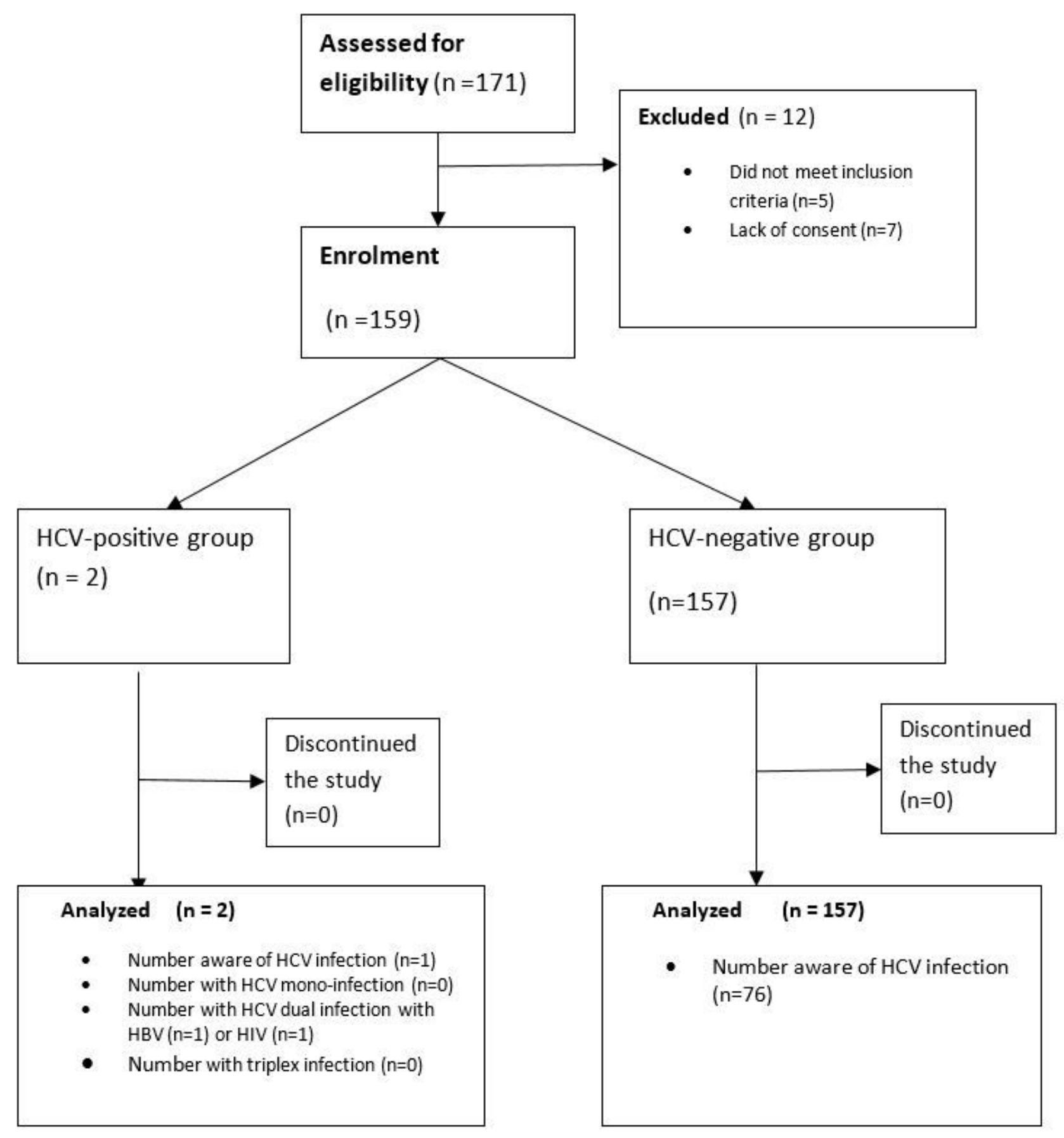

Figure 1

Flow chart of the study participants

\section{Supplementary Files}

This is a list of supplementary files associated with this preprint. Click to download.

- Table1.jpg 
- Table2.jpg

- Table3.jpg

- Table4.jpg

- PILOTSTUDYSubmittedexcelHCV.xls 